\title{
Insensible Water Loss and Metabolic Rate in Low Birthweight Newborn Infants
}

\author{
A. OKKEN, J. H. P. JONXIS, P. RISPENS, AND W. G. ZIJLSTRA
}

Department of Pediatrics and the Laboratory of Chemical Physiology, University of Groningen, the Netherlands

\begin{abstract}
Summary
Insensible water loss (IWL) and metabolic rate (MR) were measured simultaneously in three groups of low birthweight (LBW) infants in a special incubator with air and wall temperature separately controlled as to keep the infants in their neutral thermal environment. Group I infants $(n=7)$ had a birthweight of 1.125 $\pm 0.192 \mathrm{~kg}$ and a gestational age of $20.0 \pm 0.6 \mathrm{wk}$; group II infants $(n=8)$ had a birthweight of $1.730 \pm 0.440 \mathrm{~kg}$ and a gestational age of $33.0 \pm 1.6 \mathrm{wk}$, and group III infants $(n=7)$ had a birthweight of $1.960 \pm 0.230 \mathrm{~kg}$ and a gestational age of $38.3 \pm 1.9 \mathrm{wk}$ (small for dates).

In group I infants, IWL decreased significantly $(P<0.05)$ between the 1st and the 2 nd wk of life from $54.1 \pm 11.2$ to $42.7 \pm$ $12.7 \mathrm{ml} \cdot \mathrm{kg} \cdot \mathrm{d}^{-1}$, whereas $\mathrm{MR}$ increased significantly $(P<0.01)$ from $48.8 \pm 6.7$ to $57.5 \pm 8.0 \mathrm{kcal} \cdot \mathrm{kg}^{\circ} \mathrm{d}^{-1}$. In group II infants, IWL in the 2nd wk of life was not significantly different from IWL in the 1st wk of life which was $26.3 \pm 5.6 \mathrm{ml} \cdot \mathrm{kg}^{-1} \cdot \mathrm{d}^{-1}, \mathrm{MR}$ increased significantly $(P<0.001)$ from $45.7 \pm 6.2 \mathrm{kcal} \cdot \mathrm{kg}^{-1} \cdot \mathrm{d}^{-1}$ in the 1 st wk of life to $55.1 \pm 6.3 \mathrm{kcal} \cdot \mathrm{kg}^{-1} \cdot \mathrm{d}^{-1} \cdot \mathrm{d}^{-1}$ in the $2 \mathrm{nd}$ wk of life. In group III infants, IWL increased significantly $(P<$ $0.05)$ between the 1 st and 2 nd wk of life from $23.7 \pm 7.5$ to 31.9 $\pm 9.4 \mathrm{ml} \cdot \mathrm{kg}^{-1} \cdot \mathrm{d}^{-1}$ with a concomittant increase in MR $(P<0.01)$ from $48.8 \pm 7.1$ to $61.0 \pm 8.4 \mathrm{kcal} \cdot \mathrm{kg}^{-1} \cdot \mathrm{d}^{-1}$.

It is concluded that very $L B W$ preterm infants in a neutral thermal environment have an increased evaporation through the skin resulting in an IWL that is much higher than expected from their MR, and that minimization of heat loss by radiation and convection is necessary to keep the infants in thermal equilibrium without a fall in body temperature and an increase in heat production.
\end{abstract}

\section{Speculation}

Separate air and wall heating and extremely low air velocity may be important features of incubators to be designed for very LBW preterm infants.

Several investigators have shown that LBW infants have large insensible water losses when in conventional incubators $(2,11)$, under radiant heaters $(11)$, and under phototherapy $(8,11)$. Fanaroff $e t$ al. (2) demonstrated that in conventional incubators IWL is strongly affected by the environmental conditions close to the infant. This was demonstrated by the remarkable reduction of the large IWL of very LBW infants in a single-walled convention incubator which was obtained by covering the infant with an open-ended plastic shield (heat shield) $(5,6)$. However, even under the heat shield, IWL still exceeded the basal values as reported by Hey and Katz (3). This was an unexpected finding, because the infants under the heat shield were in their neutral thermal environment $(5,6)$. Assuming that MR in their infants was not increased, Fanaroff et al. (2) suggested that very LBW premature infants may have an increased evaporation through the skin.

Increased evaporation through the skin in very LBW premature infants in their neutral thermal environment will not only affect total water loss, but consequently evaporative heat loss. This may have consequences as to the design and adjustment of the incubator necessary to keep the infants in their optimum environment.

In the present investigation, MR and IWL were simultaneously measured in LBW and very LBW premature infants. The infants were at their neutral thermal environment in an incubator with separate air and wall heating and extremely low air velocity.

\section{MATERIALS AND METHODS}

IWL and MR were measured simultaneously in three groups of LBW infants in the 1st and 2nd wk of life. Birthweight and gestational age ranged from $0.88-1.35 \mathrm{~kg}$ and from $28-30 \mathrm{wk}$ in group I infants, from $1.35-2.45 \mathrm{~kg}$ and from $31-35 \mathrm{wk}$ in group II infants, and from $1.53-2.13 \mathrm{~kg}$ and from $36-41 \mathrm{wk}$ in group III infants. Mean birthweight and gestational age are presented in Table 1. According to Dutch standards, group I and group II infants had birthweights appropriate for gestational age, group III infants had birthweights below the 2.3 percentile (small for dates).

At the time of the study, all infants were in good health except for their low birthweight. During the measurements they were asleep with only occasional body movements. A milk formula (Nutricia, Almiron A) was supplied by continuous gastric drip. Additionally, glucose was administered iv in the majority of the infants. No drugs were used apart from antibiotics in four infants.

All infants were studied naked in a specially constructed incubator in which the temperature of the air and the walls could be regulated independently (Fig. 1). Temperature of the incubator wall was measured at five sites using thermocouples let into the perspex wall. Mean wall temperature was calculated from these measurements assuming that the reading from each thermocouple represented the temperature of a certain area. The temperature of the air was measured with thermocouples in the inflow and outflow tubes of the incubator; the average of the two readings was taken. Rectal temperature and skin temperature (abdomen) were also measured with thermocouples. All thermocouples were connected to a switch box and could be read one at a time on a galvanometer scale (Ellab TE3). Temperatures were read at $5 \mathrm{~min}$ intervals. Air and wall temperature were adjusted for birthweight and postnatal age according to Hey and Katz (4). This resulted in the infant being at its neutral temperature. Air velocity was measured by means of a thermoelectric anemometer (Instituut voor Gezondsheidstechniek T.N.O., Delft, The Netherlands) at 1$2 \mathrm{~cm}$ above the abdomen of the infant in the incubator. The air velocity never exceeded $0.05 \mathrm{~m} \cdot \mathrm{s}^{-1}$. Humidity in the incubator was read at $5 \mathrm{~min}$ intervals from a hygrometer (Thies); during the measurement of $\mathrm{O}_{2}$ consumption $\left(\mathrm{VO}_{2}\right)$ and $\mathrm{CO}_{2}$ production $\left(\dot{\mathrm{VCO}}_{2}\right)$ water vapor pressure $\left(\mathrm{PH}_{2} \mathrm{O}\right)$ was determined in a sample of incubator air using a psychrometer (Haenni).

IWL was obtained from the continuous recording of weight loss $\left(\Delta \mathrm{m}_{\mathrm{b}}\right)$ measured by means of a specially constructed balance (Fig. 2 ). This balance is composed of a heavy underframe $(0)$, on which two supporting beams (D) are mounted. The supporting beams carry on the one side a weighing platform $(P)$ and on the other side a counter weight $(C)$. The connections between underframe 
Table 1. Birthweight, gestational age, age at the time of study, air temperature $\left(T_{A}\right)$, wall temperature $\left(T_{W}\right)$ and water vapor pressure $\left(\mathrm{PH}_{2} \mathrm{O}\right)$ in the incubator and rectal $\left(T_{R}\right)$ and skin temperature $\left(T_{S}\right)$ of the infants ${ }^{1}$

\begin{tabular}{|c|c|c|c|c|c|c|c|c|}
\hline Group & $\begin{array}{c}\text { Birthweight } \\
\text { (kg) }\end{array}$ & $\begin{array}{c}\text { Gestational } \\
\text { age (wk) }\end{array}$ & Age (days) & $\mathrm{T}_{\mathrm{A}}\left({ }^{\circ} \mathrm{C}\right)$ & $\mathrm{T}_{\mathrm{w}}\left({ }^{\circ} \mathrm{C}\right)$ & $\begin{array}{c}\mathrm{PH}_{2} \mathrm{O} \\
(\mathrm{mm} \mathrm{Hg})\end{array}$ & $\mathrm{T}_{\mathrm{K}}\left({ }^{\circ} \mathrm{C}\right)$ & $\mathrm{T}_{S}\left({ }^{\circ} \mathrm{C}\right)$ \\
\hline \multirow[t]{2}{*}{ I $(n=7)$} & $1.125 \pm 0.192$ & $29.0 \pm 0.6$ & $3.6 \pm 2.1$ & $34.7 \pm 0.3$ & $34.7 \pm 0.3$ & $13.1 \pm 1.9$ & $36.1 \pm 0.3$ & $35.7 \pm 0.3$ \\
\hline & & & $11.7 \pm 2.5$ & $34.4 \pm 0.7$ & $34.5 \pm 0.7$ & $13.1 \pm 2.4$ & $36.8 \pm 0.2$ & $36.4 \pm 0.2$ \\
\hline \multirow[t]{2}{*}{ II $(n=8)$} & $1.730 \pm 0.440$ & $33.0 \pm 1.6$ & $4.0 \pm 2.2$ & $34.2 \pm 0.6$ & $34.1 \pm 0.6$ & $15.0 \pm 2.3$ & $36.8 \pm 0.3$ & $36.5 \pm 0.4$ \\
\hline & & & $10.7 \pm 2.4$ & $33.3 \pm 0.7$ & $33.0 \pm 0.7$ & $14.5 \pm 2.6$ & $37.0 \pm 0.2$ & $36.5 \pm 0.2$ \\
\hline \multirow[t]{2}{*}{ III $(n=7)$} & $1.960 \pm 0.230$ & $38.3 \pm 1.9$ & $3.7 \pm 2.2$ & $34.1 \pm 0.8$ & $33.7 \pm 0.5$ & $14.3 \pm 1.2$ & $36.9 \pm 0.4$ & $36.6 \pm 0.2$ \\
\hline & & & $11.2 \pm 2.4$ & $33.4 \pm 0.5$ & $33.1 \pm 0.6$ & $13.5 \pm 0.9$ & $37.0 \pm 0.2$ & $36.6 \pm 0.1$ \\
\hline
\end{tabular}

'All data are expressed as mean \pm SD.

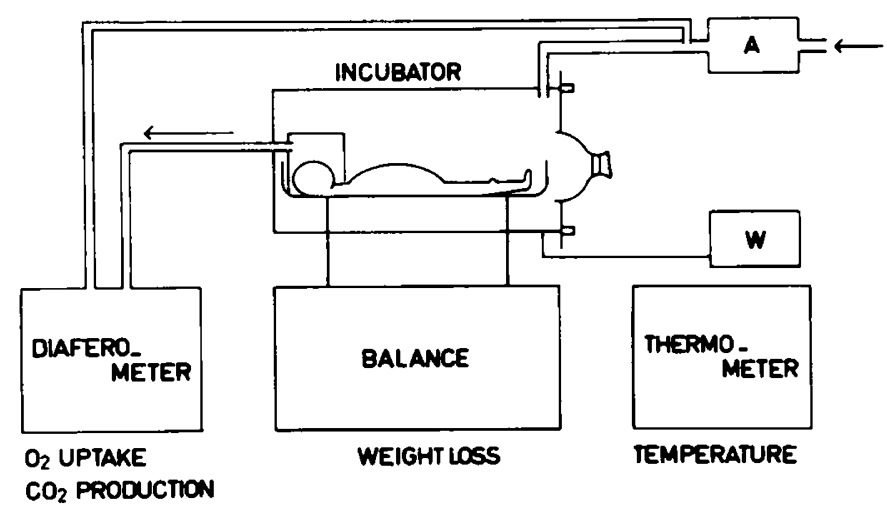

Fig. 1. Schematic drawing of the experimental design. The rectangles at the right represent the heating systems for incubator air $(A)$ and incubator wall $(W)$. The electrical thermometer is connected to thermocouples at various sites. A balance is used for the continuous recording of weight loss. $\mathrm{O}_{2}$ consumption and $\mathrm{CO}_{2}$ production are determined by means of a diaferometer.

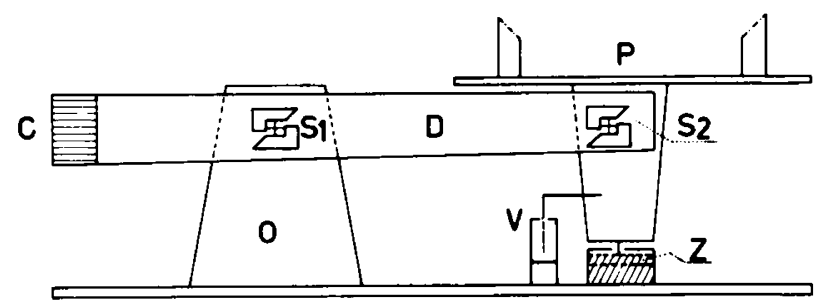

Fig. 2. Special balance used for the determination of insensible water loss. $C$, counter weight; $D$, supporting beams; $O$, underframe; $P$, weighing platform; $S_{1}$ and $S_{2}$, spring-mounted hinges; $V$, displacement transducer; $Z$, piston in oil bath.

and supporting beams and between supporting beams and weighing platform are made by spring-mounted hinges ( $\mathrm{S} 1$ and $\mathrm{S} 2$ ). The weighing platform can move upwards and downwards in horizontal position, with a maximum deflection of a $\mathrm{few} \mathrm{cm}$. The movements of the weighing platform are damped by means of a piston in an oil-bath $(Z)$. The infant lies on a nylon net in the incubator, which is connected to the weighing platform by means of gastight, nearly frictionless connectors through the incubator wall. The load on the weighing platform is independent of the weight of the infant, because the balance is brought into equilibrium by adding weights to the platform. The deflection of the weighing platform is measured by means of a displacement transducer (V) and a potentiometric recorder (Philips PM8010). During each measuring period the calibration of the system is checked by removing and adding a weight of $1 \mathrm{~g}$ (Fig. 3).

Diapers or clothes, which can absorb or release an appreciable amount of water were not used. Absorption or release of water by the nylon net underneath the infant was negligible. To prevent urine and stool from influencing the measurements, a watertight plastic bag was carefully attached to the infant, enclosing both the

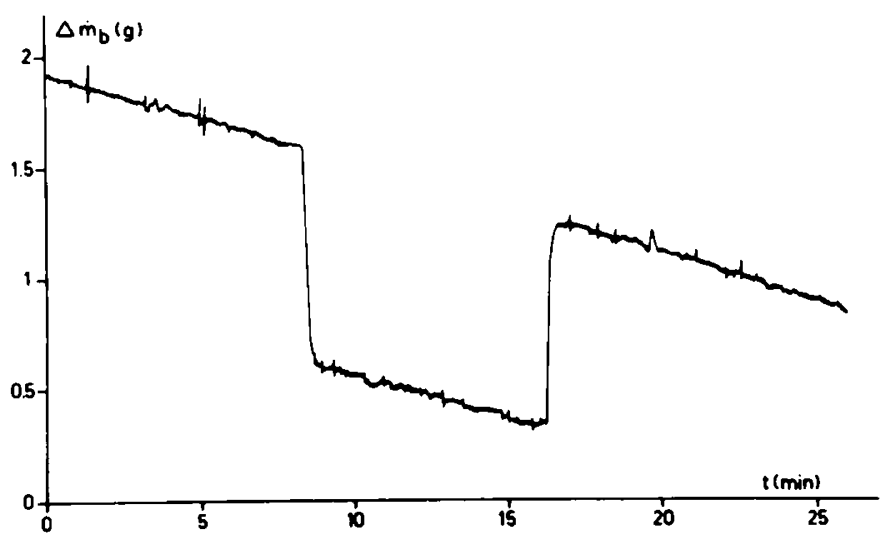

Fig. 3. Recording of weight loss $\left(\Delta \dot{m}_{b}\right)$ of a $2.2 \mathrm{~kg}$ infant. For calibration of the weighing system, a weight of $1 \mathrm{~g}$ is taken from the balance and subsequently added again.

anal and the genital area. Feeding by intragastric catheter and iv administration of fluid was continued during the measurements. This had no influence on the recorded decrease in weight, because food and infusion fluids were with the infant on the balance. The infant was continuously observed and the measurement terminated when any leakage of food, infusion fluid, urine or stool occurred, or when sweating was observed. A typical record of the decrease in weight of an infant is shown in Figure 3.

The continuous decrease in weight is, apart from the IWL, determined by the difference in weight between the $\mathrm{O}_{2}$ consumed and the $\mathrm{CO}_{2}$ produced. A correction for this factor could be carried out, because $\dot{\mathrm{VO}}{ }_{2}$ and $\dot{\mathrm{V}} \mathrm{CO}_{2}$ of the infant were measured simultaneously with the recording of the change in weight. For calculating IWL the following equation was used (9):

$$
\mathrm{IWL}=\Delta \dot{\mathrm{m}}_{\mathrm{b}}-1.977 \dot{\mathrm{V}} \mathrm{CO}_{2}+1.429 \dot{\mathrm{VO}}_{2}
$$

where IWL and $\dot{\mathrm{m}}_{\mathrm{b}}$ are in $\mathrm{mg} \cdot \mathrm{min}^{-1}$ and $\dot{\mathrm{VO}}_{2}$ and $\dot{\mathrm{VCO}} \mathrm{O}_{2}$ in $\mathrm{ml}$. $\min ^{-1}$.

MR was obtained from the simultaneous recording of the infant's $\dot{\mathrm{V}} \mathrm{O}_{2}$ and $\dot{\mathrm{V}} \mathrm{CO}_{2}$ measured by means of a thermal conduc- tivity method carried out with a Kipp diaferometer which was calibrated with human expiratory gas (10). A mixture of the infant's expiratory gas and incubator air was drawn with an exactly known flow rate from a hood around the infant's head (open method) (Fig. 1). Reference gas was taken from the air inlet of the incubator. The deflections of the independent $\mathrm{O}_{2}$ and $\mathrm{CO}_{2}$ channels of the diaferometer were recorded continuously (Kipp BD5/BE5). For calculating MR the following equation was used (9):

$$
\mathrm{MR}=3.797 \dot{\mathrm{V}} \mathrm{O}_{2}+1.204 \dot{\mathrm{V}} \mathrm{CO}_{2}
$$

where $\mathrm{MR}$ is expressed in $\mathrm{cal} \cdot \mathrm{min}^{-1}$ and $\mathrm{V}_{2}$ and $\dot{\mathrm{VCO}} \mathrm{C}_{2}$ in $\mathrm{ml}$. $\min ^{-1}$ (STPD).

For statistical evaluation of the data a two-tailed paired $t$-test and rank sum test (Wilcoxon) were used. Informed consent from the parents was obtained. 


\section{ACCURACY OF THE METHODS}

IWL was determined by continuous weighing. The overall accuracy of the weighing system was estimated to be $0.4 \%$. In calculating IWL from $\dot{\mathrm{m}}_{\mathrm{b}}$, a correction has to be made for the difference in weight between $\mathrm{O}_{2}$ consumed and $\mathrm{CO}_{2}$ produced. Omission of this correction may result in a considerable overestimation of IWL. If evaporation is low and the respiratory quotient high, an error $>20 \%$ may easily occur. Taking the accuracy of measuring $\mathrm{V}_{2}$ and $\dot{\mathrm{V}} \mathrm{CO}_{2}$ into account, we found that the accuracy with which IWL has been determined, varies from 3-9\%, depending on the value of $\dot{\mathrm{m}}_{\mathrm{b}}(9)$.

To increase the accuracy of the measurement of $\dot{\mathrm{VO}}_{2}$ and $\dot{\mathrm{VCO}}_{2}$, the diaferometer used in this study was calibrated several times using human expiratory gas (10). This resulted in an accuracy for the determination of both $\dot{\mathrm{VO}}_{2}$ and $\dot{\mathrm{V}} \mathrm{CO}_{2}$ of $4 \%$. The methods for calculating $\mathrm{MR}$ from $\mathrm{VO}_{2}$ and $\mathrm{VCO}_{2}$ were critically reviewed (9). As a consequence, equation 2 was formed, allowing the calculation of MR with an overall accuracy of about $4 \%$.

\section{RESULTS}

A total of 83 measurements were obtained in 22 infants. Mean birthweight, gestational age, age at the time of the study, incubator air, and wall temperature, and $\mathrm{PH}_{2} \mathrm{O}$ in the incubator, and rectal and skin temperature of the infants are represented in Table 1. Birthweight and gestational age in group I infant are significantly less than in group II infants $(P<0.001)$. Birthweights of group II and group III infants are not significantly different, although mean birthweight is lower in group II than in group III. At the time of the first study, the mean age in each group was between 3.6 and 4.0 days and at the time of the second study between 10.7 and 11.7 days $(P<0.001)$. There is no significant difference between age at the time of the first study in group I, II, and III infants. The same holds for the second study.

Incubator air and wall temperature were adjusted for birthweight and age according to Hey and Katz (4). This does account for the differences in incubator temperature between the three groups as well as between the infants within each group. $\mathrm{PH}_{2} \mathrm{O}$ was slightly less in group $\mathrm{I}$ infants when compared to $\mathrm{PH}_{2} \mathrm{O}$ in group II infants. This difference is significant $(P<0.01)$ for the first study, but not for the second one. In group III infants, $\mathrm{PH}_{2} \mathrm{O}$ during the second study was slightly but significantly $(P<0.05)$ less than $\mathrm{PH}_{2} \mathrm{O}$. At the time of the first study, rectal and skin temperature in group $I$ infants were significantly lower than in group II and III infants $(P<0.001)$. At the time of the second study, this difference had disappeared.

Data on IWL and MR are presented in Table 2. Both during the first and the second study, IWL in group I infants was significantly larger than in group II and III infants $(P<0.01)$. In group I infants, IWL at the time of the first study was significantly larger $(P<0.001)$ than at the time of the second study. In contrast, in group III infants, IWL at the time of the first study was significantly less than at the time of the second study $(P<0.001)$. In group II infants, there was no significant difference.

Both during the first and the second study there were no significant differences in MR between the three groups of infants. However, in all three groups, MR at the time of the second study was significantly higher than at the time of the first study $(P<$ 0.01 ).

\section{DISCUSSION}

In this investigation, infants were studied in their neutral thermal environment as defined by Hey and Katz (4) in an incubator with separately controlled air and wall temperature, low air velocity, and moderate humidity. This incubator was of similar design as that of Hey and Katz (3). Analogous to their results, IWL in our infants was lower than that in infants in conventional convection incubators and under radiant heaters $(2,8,11)$. However, in contrast to Hey and Katz (3) who reported no difference in IWL/ $\mathrm{m}^{2}$ body surface area in infants from $1.0-4.5 \mathrm{~kg}$ of bodyweight, we found a considerably higher IWL in very LBW infants (group I) as compared with infants with higher birthweight (groups II and III).

The evaporation of water from the skin and airways is depen-
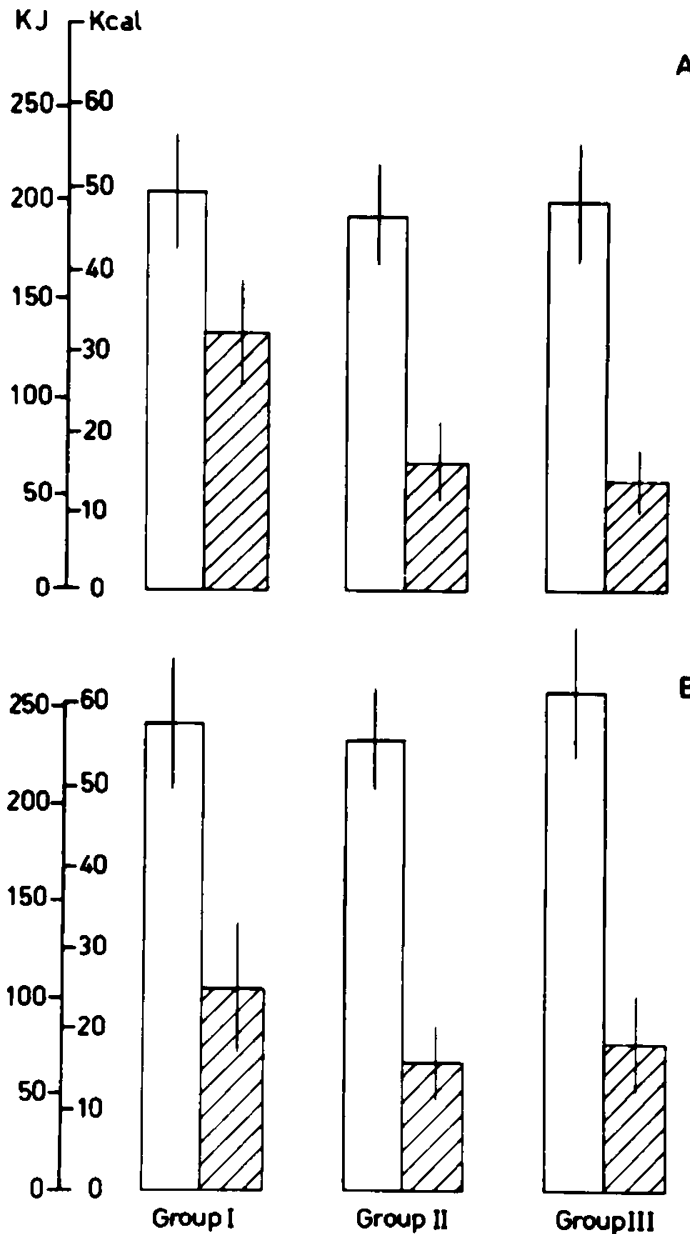

Fig. 4. Heat production (white columns) and evaporative heat loss (hatched columns) in group I (birthweight $1.125 \pm 0.192 \mathrm{~kg}$ and gestational age of $29.0 \pm 0.6 \mathrm{wk}$ ), group II (birthweight $1.730 \pm 0.440 \mathrm{~kg}$ and gestational age of $33.0 \pm 1.6 \mathrm{wk}$ ) and group III (birthweight $1.960 \pm 0.230$ $\mathrm{kg}$ and gestational age of $38.3 \pm 1.9 \mathrm{wk})$ infants during the $1 \mathrm{st}(A)$ and the 2nd $(B)$ wk of life. Heat production and heat loss on the vertical axis are in $\mathrm{KJ} / \mathrm{kg}$ bodyweight/day and in $\mathrm{kcal} / \mathrm{kg}$ bodyweight/day.

Table 2. IWL and MR in LBW infants ${ }^{1}$

\begin{tabular}{|c|c|c|c|c|c|c|c|}
\hline \multirow{4}{*}{$\frac{\text { Group }}{\text { I }}$} & \multirow{4}{*}{$\begin{array}{r}\text { Age (days) } \\
3.6 \pm 2.1 \\
11.7 \pm 2.5\end{array}$} & \multicolumn{3}{|c|}{ IWL } & \multicolumn{3}{|c|}{ MR } \\
\hline & & \multirow{3}{*}{$\begin{array}{c}\left(\mathrm{ml} \cdot \mathrm{kg}^{-1} \cdot \mathrm{d}^{-1}\right) \\
54.1 \pm 11.2 \\
42.7 \pm 12.7\end{array}$} & \multicolumn{2}{|c|}{$\left(\mathrm{ml} \cdot \mathrm{m}^{-2} \cdot \mathrm{d}^{-1}\right)$} & \multirow{3}{*}{$\begin{array}{c}\left(\mathrm{kcal} \cdot \mathrm{kg}^{-1} \cdot \mathrm{d}^{-1}\right) \\
48.8 \pm 6.7 \\
57.5 \pm 8.0\end{array}$} & \multicolumn{2}{|c|}{$\left(\mathrm{kcal} \cdot \mathrm{m}^{-2} \cdot \mathrm{d}^{-1}\right)$} \\
\hline & & & $568 . \pm 127.0$ & & & $509.8 \pm 66.2$ & \\
\hline & & & $449.0 \pm 135.1$ & $P<0.05$ & & $603.4 \pm 73.4$ & $P<0.01$ \\
\hline \multirow[t]{2}{*}{ II } & $4.0 \pm 2.2$ & $26.3 \pm 5.6$ & $307.9 \pm 60.0$ & & $45.7 \pm 6.2$ & $537.8 \pm 83.0$ & \\
\hline & $10.7 \pm 2.4$ & $26.7 \pm 6.5$ & $324.0 \pm 62.9$ & NS & $55.1 \pm 6.3$ & $678.0 \pm 94.1$ & $P<0.001$ \\
\hline \multirow[t]{2}{*}{ III } & $3.7 \pm 2.2$ & $23.7 \pm 7.5$ & $302.2 \pm 101.8$ & & $48.8 \pm 7.1$ & $621.6 \pm 103.2$ & \\
\hline & $11.2 \pm 2.4$ & $31.9 \pm 9.4$ & $398.2 \pm 106.8$ & $P<0.05$ & $61.0 \pm 8.4$ & $765.1 \pm 114.0$ & $P<0.01$ \\
\hline
\end{tabular}

\footnotetext{
' All data are expressed as mean $\pm \mathrm{SD}$.
} 
dent on environmental factors (air and wall temperature, humidity, air velocity) and infant factors (body temperature, posture, metabolic rate). During our measurements, air and wall temperature were kept at the level advised by Hey and Katz (3). Humidity in our incubator, however, was slightly lower than in their metabolic changer $\left(\mathrm{PH}_{2} \mathrm{O}=13\right.$ and $18 \mathrm{~mm} \mathrm{Hg}$, respectively). This slight difference may have caused the somewhat larger IWL in all our infants, but cannot explain the larger insensible water losses in the infants of our group I.

Another difference between our set-up and that of other investigators $(2,3,11)$ was that in our incubator the infant was lying on a Nylon net, whereas in the other studies, it was placed on a mattress or a Perspex plate. In our opinion, however, the ensuing difference in body surface area available for evaporation, can hardly explain the considerably increased IWL in our group I infants, although it might explain the slightly increased IWL in group II and III infants.

Mature infants sweat in a hot environment when rectal temperature rises above $37.2^{\circ} \mathrm{C}$, but their ability to sweat is limited (3). In LBW infants the ability to sweat is even less. In our infants mean rectal temperature during the measurements did not exceed $37.0^{\circ} \mathrm{C}$. Consequently, sweating may be excluded as a contributing factor causing the higher IWL in our infants.

The influence of posture and activity on IWL has been studied by Zweymüller and Preining (12) in a group of newborn infants with birthweights of $2.4-4.6 \mathrm{~kg}$. In actively moving infants IWL was shown to be increased as much as $65 \%$ in comparison with the sleeping condition. During our measurements the infants were usually asleep, but some moved quietly during part of the observation period. This may have increased IWL to some extent, but the functional state of our babies does not seem to have been appreciably different from that of the infants studied by others.

Hey and Katz (3) studied the relationship between IWL and MR. Using their equation (3) we calculated a smaller IWL from our MR measurements than we found experimentally. This especially holds for our group I infants where we found that the experimentally determined IWL values were $100-155 \%$ higher than the calculated ones. In our group II and III infants, the differences were much less (29-52\% and $30-41 \%$, respectively). Our study thus shows that IWL in very LBW preterm infants is out of proportion to MR. This also follows from the observation that in very LBW infants (group I, Table 2) IWL at the age of 3.6 days is significantly larger than at 11.7 days, whereas MR at 3.6 days is significantly less than 11.7 days.

Although the cause of the discrepancy between our findings and those of Hey and Katz (3) cannot be traced on the ground of the data reported in the literature, we have found an increased IWL in very premature infants in their neutral thermal environment. The supposition of Fanaroff et al. (2) that below a critical level of maturity, IWL through the skin is out of proportion to MR, seems quire reasonable. Additional evidence for this hypothesis can be found in the difference in IWL between group I, group II, and group III infants at comparable ages and similar MR. In the group I infants, the skin will be in an early stage of maturation with corresponding high permeability. In all infants of groups II and III, maturation of the skin will have proceeded resulting in much less permeability. The decrease in IWL of the group I infants between the 1st and 2 nd wk of life despite an increase in MR indicates that the permeability of the skin has decreased. This observation is of particular clinical significance. It indicates that the water requirement of very $\mathrm{LBW}$ infants decreases rapidly. The amount of water supplied to these infants should not be based on a standard prescription, but adjusted to individual needs.

Evaporative heat loss, as calculated from IWL in comparison with total heat loss is shown in Figure 4. Assuming that $T_{R}$ and $T_{S}$ adequately represent overall body temperature MR equals total heat loss when $T_{R}$ and $T_{S}$ are stable. This allows to express evaporative heat loss as a fraction of total heal loss. Thus, in group III infants evaporative heat loss accounts for 28 and $30 \%$ of total heat loss for the first and second study, respectively. In group II infants this is $35 \%$, and $29 \%$ in the first and second study. These data are in accordance with those generally accepted in the literature where evaporative heat loss is given as $20-30 \%$ of total heat loss. In group I infants, however, this is much higher: $65 \%$ in the first study and $43 \%$ in the second one. In these infants evaporative heat loss, thus, is a much higher fraction of total heat loss. Heat loss by radiation and convection was correspondingly lower. As heat loss by radiation and convection depends on incubator wall and air temperature, the low radiative and conductive heat loss could only be accomplished by adjusting air and wall temperature. Minimization of heat loss by radiation and convection is absolutely necessary in order to keep very LBW preterm infants with their high evaporative heat loss in thermal equilibrium without a fall in body temperature and a rise in heat production. In a conventional convection incubator with a relatively cold incubator wall this would not have been possible.

Controlling heat loss by radiation and convection is most effectively done by separately heating incubator air and incubator wall. This makes incubator wall temperature independent of room temperature. Moreover, it obviates the demand for a higher air velocity to improve heating of the incubator walls. A higher air velocity increases evaporative heat loss, which again leads to the necessity of humidifying the inflowing air. This is demonstrated by the observation of Belgaumkar and Scott (1) that the rectal temperature of newborn infants nursed in a servo-controlled convection incubator, could be kept from falling only when the inflowing air was humidified. The results of this study suggest that separate air and wall heating and extremely low air velocity may be important features of future incubator designs for very LBW premature infants.

The results of our study do not explain why very LBW preterm infants in convection incubators and under radiant heaters have such very large insensible water losses. We suggest, however, that the increased evaporation through the skin will make the very premature infant more susceptible for the physical properties of its environment. Not only does their relatively large body surface area increase their susceptibility for the environmental factors that affect radiant and convective heat losses, in addition, will their increased evaporation through the skin increase their susceptibility for the environmental factors that affect evaporative heat losses. In other words, in incubators and other heat-supplying devices used for very LBW premature infants not only controlled air and wall (radiant) heating, but also controlled air velocity and humidity are important features.

\section{REFERENCES AND NOTES}

I. Belgaumkar, T. K., Scott, K. E.: Effects of low humidity on small premature infants in servo control incubators. Biol. Neonate, 26: 337 (1975).

2. Fanaroff, M.. Wald, M.. Gruber, H. S., Klaus, M. H.: Insensible water loss in low birth weight infants. Pediatrics, 50: 236 (1972).

3. Hey, E. N., Katz, G.: Evaporative water loss in the newborn baby. J. Physiol. 200: $605(1969)$

4. Hey, E. N., Katz, G.: The optimum thermal environment for naked babies. Arch. Dis. Childhood, 45: 328 (1975).

5. Hey, E. N., Mount. L. E.: Heat losses from babies in incubators. Arch. Dis. Childhood, 45: 328 (1975).

6. Hey, E. N., Mount, L. E.: Temperature control in incubators. Lancet, 2: 202 (1966).

7. Kloosterman, G. J.: On intra-uterine growth. The significance of prenatal care. Int. J. Gynecol. Obstet., 8: 895 (1970).

8. Oh, W., Karechi, H.: Phototherapy and insensible water loss in the newborn infant. Amer. J. Dis. Child., 124: 230 (1972)

9. Okken, A.: Heat balance in low birthweight newborn infants. Thesis, Groningen, The Netherlands. (1976)

10. Ten Hoor, F., Rispens, P., Van de Wall, E., Zijlstra, W. G.: Determination of oxygen uptake and carbon dioxide production in animals and man using a diaferometer calibrated with expired gas. Application in the direct Fick procedure for determining cardiac output. Proc. Kon. Ned. Akad. Wet., Series C77: 429 (1974)

11. Wu, P. Y. K., Hodgman, J. E.: Insensible water loss in preterm infants: changes with postnatal development and non-ionizing radiant energy. Pediatrics, 54: 704 (1974)

12. Zweymüller, E., Preining. O.: The insensible water loss of the newborn infant. Acta Paediatr Scand. (Suppl): 205 (1970)

13. Received for publication July 26, 1978

14. Accepted for publication September 21, 1978. 